\title{
Creating a public tool to assess and promote transparency in global land deals: The experience of the Land Matrix
}

\author{
ANSEEUW, W; GIGER, M.; ALTHOFF, C.; MESSERLI, P.; NOLTE, K.; TAYLOR, M.; SEELAFF, A.
}

The Beta version of the Land Matrix (http://landportal.info/landmatrix) was launched in April 2012 as a tool to promote public participation in building a constantly evolving database on large-scale land acquisitions (LSLA), and making the data visible and understandable. The aim of the Land Matrix partnership $^{1}$ is to promote transparency and open data in decision-making over land and investment, as a step towards greater accountability. Since its launch, the Land Matrix (LM) has attracted a high degree of attention, and stirred some controversy. It provides valuable lessons on the challenges and successes of promoting open data on practices that are often shrouded in secrecy.

This paper critically examines the on-going efforts by the LM partnership to build a public tool to promote greater transparency in decision-making over land and investment at a global level. It intends to provoke discussion of the extent to which such a tool can ultimately achieve its goals of improved transparency and accountability. It will first present some key characteristics of the LM and its value-addition, followed by details of the challenges it encountered related to the assessment of trends, scale and nature of the LSLA phenomenon. Finally, the paper will specify how these issues are being addressed, aiming at establishing a dynamic and participatory tool for open development.

\section{The Land Matrix - Basic concept, rationale and value addition}

Since 2009, the LM has been systematically collating and verifying information on LSLA. It records cases of announced, intended and realized transactions that entail a transfer of rights to use, control or own land through sale, lease or concession that are 200 ha or larger; and that have been instigated since the year 2000. It mainly focuses on transactions that involve foreign investors, although domestic cases have also been documented. The data come from a variety of sources that include media reports, reports by international organizations and NGOs as well as academic research based on field-research projects. These different reports are mainly being sourced through the two most active Internet portals that deal with land transactions: www.commercialpressuresonland.org of the International Land Coalition (ILC) and partners, and www.farmlandgrab.org operated by the NGO GRAIN. Data also come from public participation, through a crowd-sourcing approach (Howe, 2006; Bott 2011). As such, the interface invites users to comment on deals and to provide information on deals not included in the database. In addition to its related data visibility, it contributes to public participation and awareness and has been feeding the debate regarding the large-scale land acquisition phenomenon.

A major value addition of the LM has been the cross-verification of the data made public - a feature that other media-based inventories did not include (Cotula, 2012). In the Beta version, data have

\footnotetext{
${ }^{1}$ Formed by the Centre for Development and Environment (CDE) at the University of Bern, Centre de cooperation ninternationale en recherche agronomique pour le développement (CIRAD), German Institute of Global and Area Studies (GIGA), Gesellschaft für Internationale Zusammenarbeit (GIZ) and the International Land Coalition (ILC).
} 
been classified according to four levels of reliability. More specifically, a reliability ranking between 0 and 3 was introduced:

- Reliability ranking 0 - cases only reported by the press or other sources;

- Reliability ranking 1 -cases reported by sources that are judged reliable, more specifically cases reported in research papers based on empirical research, company websites, government records, or other reliable sources considered on a case-by-case basis;

- Reliability ranking 2 - cases that have been checked through field verification by partner organisations in the countries;

- Reliability ranking 3 - deals where contractual agreements have been made publicly available. Only data judged reliable, i.e. level 1 or higher, are published on the LM website - a decision initially made to safeguard the LM's credibility and to avoid legal reactions.

At its launch, the LM contained slightly over 1,000 cases of land deals with reliability ranking 1 or higher. These publicly made deals represented about $50 \%$ of all the deals included in the 'internal' database. The initial LM Beta version reported, intended and realized deals at any level of implementation, i.e. deals under negotiation, completed, and also failed deals. The initial reason for such a comprehensive definition of land transactions was to display interest in and demand for land. The initial objective of the LM was to publish the totality of the cases in the database, in order to make available as much information as possible with regards LSLA and investments.

Besides being an instrument of open data aiming at making the data visible and understandable, the LM is as such also a tool promoting transparency in decision-making over land and investment, as a step towards greater accountability. The LM can therefore be seen an endeavour that complements a movement towards more open access to government data (Huijboom and Van den Broek, 2011), also refered to as Open Government Data approach (Gigler et al. 2011a; Gigler et al 2011b).

\section{Challenges of assessing trends, scale, and nature of LSLA}

There is hardly an area of (international) economic transactions that is as badly documented as (international) land transactions targeting the Global South. The dynamic nature of the phenomenon, the lacking capacities of recipient countries and the deliberate secrecy about land deals, all contribute to this deficiency. The lack of official information on large-scale land acquisitions does not only imply strong rationale to engage in data collection efforts as the LM does; it also means that there is no reference point for data collection and the assessment of the LSLA phenomenon. This is illustrated by the large number of diverse estimates of the scale of the phenomenon (see Cotula, 2012). An accurate quantification of the phenomenon remains challenging and will remain subject to change depending on applied data quality requirements, definitions and used sources (White et al., 2012).

The first challenge is hence related to defining LSLA. The LM covers land transactions of over 200 hectares and includes all land-related sectors, globally, since 2000. Both the size criterion and the sector choice induce partialities, explaining the often important differences in results and estimations. For example, it explains the disparity between the 230 million hectares reported in the "Land Rights and the Global Land Rush" report (covering all sectors, domestic and foreign deals, globally) (Anseeuw et al., 2012) and the 67 million hectares reported in the "Transnational land deals for agriculture in the Global South" (covering solely foreign deals in agriculture occurring in the South) (Anseeuw et al., 2012b). Another example concerns the biases implied by the 200ha 
threshold applied by the LM, which results in a greater focus on foreign deals (larger in size), while minimizing domestic transactions (Cotula 2012, Schönweger 2012). These considerations lead yet to another definitional defy, namely, whether or not to include domestic deals into LSLA. Again here, one may argue that the phenomenon is more about the massive conversion of different types of land into land under commercial agriculture (or other purposes) - irrespective of the origin of the investor; or even hang on to the fact that what appears to be a clear distinction at first sight foreign versus domestic investor - is actually more hazy when realities on the ground are being taken into account and that there is hardly any case of a LSLA where foreign investors are not acting through some domestic company.

This last aspect highlights the necessity to understand the nuances and details of the realities on the ground (Grain, 2012). Indeed, besides the uncertainties related to the definition of the phenomenon itself, arises the second challenge of its quantification and assessment (Chouquer, 2012). What and how do we measure the large-scale land acquisition phenomenon? Cotula (2012), for example, draws the attention on two different Ministries or Departments of the same Ministry giving diverse estimates of the very same land-based investment project. Chouquer (2012) details the Landmark deal in India which is cited by some sources as covering 150,000 ha or 5000 ha by others. Do such degrees of discrepancies reflect an error in one of the sources or is it based on certain technicalities? While data inaccuracies and reporting biases are certainly a source of inconsistency, the way of assessing LSLA is a core explanation. Based and adapted from Chouquer (2012), ten different concepts of area related to LSLA can be distinguished and include areas under negotiation, areas that are actually leased, those that go under production, and other land areas that may be affected by LSLA, for example through outgrower schemes (see box 1). Most if not all quantifications propose only one single figure for a contract or deal without indicating the underlying conceptualization of the LSLA area.

\section{Box 1: Different concepts of "area" related to large-scale land acquisitions}

Host country priority investment area: Several host countries defined agro-industrial development policies or plans and often delineated vast areas of land, which they intend to propose to investors. These offers can be the object of a policy implemented by an investment promotion agency (Agricultural Investment Support Directorate (AISD) in Ethiopia; Centro de Promoção do Investimento (CPI) in Mozambique; etc.). The concerned areas are generally high (32 million ha in Sudan; 9 million in Tchad; etc.) and can be part of broader development plans (as is the case of the Farm Blocks in Zambia for example).

Area under negotiation: The large-scale land acquisition focal area can be reduced to an area under negotiation. It concerns the land area for which governments are negotiating with investors. For example, in Sierra Leone, 480,000ha, representing $64 \%$, of the country's priority investment area, would presently be negotiated.

Optional concession area: At the same time that precise areas are leased (next level) or negotiated (previous level), companies often request options on future extensions on land that interests them or is earmarked within the framework of the country's priority investment area.

Conceded deals or leased area: it concerns the area attributed to an investor. This area is generally detailed and signed for in the framework of a contractual agreement.

Project area: These zones include at the same time the productive area (see hereafter) which forms the effective land basis for the agricultural production, as well as all the other spaces necessary for the development and functioning of the agroindustrial project.

Reserved land area: Within a concession, a company can establish a reserved land area which will remain undeveloped, at least for an undetermined time, but which is conceded and will remain available for potential future expansion.

Productive area: These areas concern the lands, on which the investment project is directly implemented. It generally includes the irrigated surfaces or the lands developed for agricultural use. This is the core of the LSLA for agro-industrial 
projects. In many cases, presently, this area covers very limited surfaces, often related to the necessary investor's engagement as stipulated in the contract in order to retain the land, such as experimental areas etc.

Additional core business impacted areas: These are areas that are not included in the investor's project but which are affected or do benefit from the core agricultural activities of the investor. Examples of these are: outgrowers schemes (of which the production is related to the investor project, labour villages, etc. The lands directly related to the project can thus cover significant land areas and are difficult to be measured.

Additional non-core business impacted areas: These are areas, which often do not have any direct link with the investor project or investors, but which are directly affected by or can benefit from it as they are necessary to the broader development of the projects. These are lands for airports and ports, the construction of power plants, etc. It also concerns the lands beyond the project that are affected by the use of certain natural resources by the agro-industrial project, such as the use of water for example, or cannot be used anymore, as the project can hinder access to it, for instance the obstruction of migration routes, etc.

Resettlement areas: This area does not situate itself in the technical continuity of the project, but at another level .These are the areas that the host government and the company use to resettle the displaced people affected by the investment. This threshold is certainly the least assessed in the literature and the least known: are they included in the land reserves of the companies? Are these effective zones or are they marginal zones occupied by landless populations.

Source: Adapted from Chouquer (2012).

These rather space-related conceptualizations indicate that the phenomenon of LSLA has an important time dimension (Deininger and Byerlee, 2010). Reflecting these dynamics is the third challenge of collating data on LSLA. The status of the land deals is indeed rapidly changing: Some move from the negotiation to the implementation phase, for other (intended) deals the negotiations never materialise, other projects collapse, etc. The pace at which land deals are decided means that static databases no longer reflect the reality on the ground. Although keeping failed or notimplemented deals in the LM database was criticised, it is certainly relevant to reflect land projects' different phases (under negotiation, signed, implementation started, production started, etc.) or different statuses (nullified, abandoned, succeeded, etc.). Also, information on projects that failed in relatively early stages does not only display interest in and the demand for land; it also reflects more comprehensively the reality of LSLA as they highlight the technical and social difficulties related to such investments. Finally, the gap between signed and effectively implemented deals may give an indication regarding land speculation. Even if they are not implemented, they exacerbate pressures on land and can lead to displacements or a weakening of land rights for the local populations (Anseeuw et al., 2012) - and should thus be assessed.

The above definitional and conceptual considerations demonstrate the considerable data requirements to adequately reflect the reality; the fourth core challenge to a quantitative assessment of LSLA. Indeed, to date, data rely mainly on media reports. Although the LM is making an effort to reduce the reliance on this type of source, availability and reliability remain problematic. Indeed, issues regarding accuracy also appear in sources considered to be more reliable, particular those classified as reliability ranking 1 which are based on research reports. Some mistakes in the data appeared from sources that are simply incorrect (probably as these reports are also based on broader media). This has led to criticism in terms of the classification of data as reliable in the LM. Ideally, data on LSLA should come from the Governments and investors themselves or be verified and updated through field visits by objective observers. However, out of the more than 1000 deals initially reported in the public interface of the LM only a negligible proportion are based on contracts that are publicly available. This is the case for only three countries, i.e. Cambodia, Liberia and Peru; only a few companies reveal information on their land-based investments. The limited information fields visible for each of these deals not only results in inaccuracies regarding specific deals, it also comparisons being made that are not always clear(for example, two different deals might be 
considered the same when limited information for these deals is available - it was often the case for the Agri-SA deal in Congo-Brazzaville, regularly located in the DRC).

Overall, the biases related to data availability, the sources used and data correctness are difficult to judge. Specific data sources may tend to focus on specific areas, investors and sectors and, subsequently, introduce biases in the data. Generally, conflict-ridden, fragile countries and countries under autocratic rule tend to provide less information, be it official data, press reports or research output. At first sight, this may lead to underestimates of LSLA in such countries. The experience from the LM, however, suggests that information on these countries often represents host country priority investment areas or areas under negotiation. The little information on the actual phase of these deals results then in aggregate figures on LSLA at country level to be over- rather than underestimated. Some biases are particularly due to media interest. This concerns for example the biases towards agricultural projects implemented by foreign investors, as much public attention has been focusing on the food (price) crises of recent years. A particular more explicit case relates to Chinese investments. Well-covered by the press, China's role in LSLA may be overestimated (Bräutigam, 2009). Only less than $20 \%$ of the deals reported by the media (included in the not published LM database with reliability ranking 0 ) could be cross-referenced and elevated to reliability ranking 1 and thus considered 'more' reliable.

\section{Towards a dynamic and participatory tool}

In the first six months after the launch of the LM, feedback was received on over 100 deals, both in the database and missing from the database. These provided valuable lessons on the challenges and successes of promoting open data on practices that are often shrouded in secrecy. In response to these comments and to the above mentioned challenges, the next version of the LM interface is presently being designed.

Firstly, the new version of the LM will show the negotiation and implementation status of each deal, also allowing filtering by implementation status. In addition, it will include separate categories like "expression of interest" in land, "negotiations failed" and "project abandoned". These categories give an indication of the scale of interest in land acquisition and allow tracking of changes to deals over time. This procedure will result in a dynamic tool, allowing to better assess the reality and the dynamics of the investments and acquisitions overall. The information thus generated will also enable observers to assess variations in dynamics and processes of each type of transaction (length of negotiation periods, presence of effective preparation phase, etc.).

Secondly, LSLA cases and, hence, data and sources, will not be ranked according to their perceived reliability anymore. Each piece of information will directly be related to its source, facilitating to filter deals by the type of source (e.g. media report, research paper, company source, crowdsourcing etc.). Thereby, users can judge themselves whether they consider the respective information reliable. This will also allow making more data available: Only deals that do not fulfil specific minimum information requirements (not allowing discerning cases from each other) will be left out. So far, about $50 \%$ of the cases and only a fraction of the variables in the database are publicly available. In the medium run, all data are meant to go online.

These methodological innovations, related to the rapidity at which the status of existing and potential land deals changes and the paucity of information readily available, imply that a greater 
emphasis is placed on first hand, primary information, that is continuously updated, instead of relying mainly on publicly available reports. It necessitates subsequently the development of strategies for continuous collecting and checking of data. This is presently implemented through several complementary modalities. First, the provision of tools to enable crowdsourcing from the public is enhanced, together with a data management system that is being developed and implemented and that automates crowdsourcing of information and its inclusion in the database through moderation. Thereby, feedback can be processed much quicker and guarantees to keep data up to date. Second, partner networks of key resource individuals and organisations in host countries are being established. For Africa, for example, besides a network of independent key informants, a partnership with the Land Policy Initiative (LPI) is being discussed, allowing, on one hand, to benefit from the LPI focal persons in each country and, on the other hand, to develop ownership and thus responsiveness through the establishment of an African portal of the LM. Lastly, a reflection is on-going to promote engagement by governments and investors listed in the database.

While the LM is - despite the mentioned conceptual and data-related problems and challenges relatively strong on providing information on the scale of the phenomenon and the broad patterns, it does not provide for the necessary project specific details and is currently weak regarding local impacts. Only for a small fraction of the land deals, the LMx has information on precise contractual arrangements, (intended) compensation or possible benefits, Such as social and productive infrastructure or job creation, or involvement of local communities. Even if contracts were available, it would still need to be confirmed in the field whether compensations were actually paid and benefits materialized. With regards to assessment of the impact dimensions of LSLA, a balance will have to be struck between the complexity of impacts and the simplicity and objectivity of indicators. More knowledge on impacts will become available as more and more research is undertaken on impacts of individual projects. The LM therefore might become important to help generalize findings from individual case studies. Also, two major additional elements are foreseen in the medium term. A first one is a mechanism of tracking the activities being implemented on the acquired lands. Such a tool can lead to better monitoring of contractual arrangements as well as the provision of information related to production patterns at project level and food security aspects at regional and national level. A second one will aim at the inclusion of land-based investments that do not involve transfer of land rights, such as outgrowing schemes, contract farming practices, etc. Beyond the effective acquisition and transactions of land, this will enlarge the scope and enable to measure the control of land-based activities by investors - i.e. aspects that are presently rather invisible and thus often overlooked (Ducastel and Anseeuw, 2011; Oya, 2012).

Complementary approaches reaching from national to local levels are indispensable in order to grab the essence and specificities of each large-scale investment project. Conversely, local tools need to link their information to a global perspective, as trans-national processes are an important feature of the phenomenon. Ultimately, transitions to more sustainable investments will be bound to institutional frameworks that embrace these scales.

Beyond the measurement of the large-scale land acquisition phenomenon - the LM as a tool for open (data) development 
The methodological challenges and the weak foundations of the data presented in this paper leave much room for interpretation, which is then often subjective and ideologically anchored. While market-friendly observers may downplay the scale of the phenomenon and may be inclined to stress the possible positive impacts of LSLA, smallholders' advocacy groups may do the opposite. Bringing more objectivity to these positions is therefore an important objective of the LM.

Important to emphasize is the contribution of the LM to broader objectives. As such, the LM is more than a tool to assess the scale of LSLA. Providing information on land acquisition is an important step towards enhancing support for more inclusive and equitable governance and social accountability. Besides the main objective of contributing to the visualization of large-scale land acquisition projects and of provision of information and public access to previously hidden data and restricted sources, the LM aims at:

- better monitoring practices implemented and the impact on people,

- promoting awareness, enhancing transparency and social accountability,

- encouraging inclusiveness of all stakeholders, in particular local populations, and empowering citizens,

- promoting responsible investment and equitable governance.

Making available the information is a key element necessary for the monitoring of the projects (are contractual arrangement being enforced, do populations benefit as agreed upon, etc.) as well as of the processes leading to the projects (were local population included in the negotiations?). As such, greater information openness does not only result in enhanced transparency and promoting awareness, it also leads to accountability and more equitable efficiency gains that ultimately should give rise to greater social and economic well-being (Gavelin et al., 2009). The danger of accepting that more benefits for all will be encouraged through better monitoring is that, as Borras and Franco (2010) rightly emphasize, LSLA will be blindly accepted and legitimized as a solution for agricultural and rural development globally. Availing information on the current patterns of agricultural investments should hence also reveal the trade-offs and opportunity costs produced in terms of social and environmental services at local but also at national and global levels (De Schutter 2011). Only by making such evidence available will it be possible to initiate a debate about the future role of agriculture and land use.

In addition, the LM as a tool of open data (Gavelin et al., 2009; Gigler et al., 2011a and 2011b; Huijboom and Van den Broek, 2011) also invites broader stakeholder engagement. This is done through its crowdsourcing instrument, but also through the direct engagement with investors and governments. As such, all stakeholders are encouraged to contribute to information dissemination through the LM and to engage with each other contributing subsequently to more inclusiveness and potential innovative and inclusive governance structures (by promoting access to information to demand more transparency, better governance, inclusiveness and by offering their own perspectives on solutions to issues confronted to). While contributing to data openness, the LM aims at enhancing the quality of governance via the empowerment of populations as well as through the "insights of the crowds" (Gigler et al., 2011, p.51).

Lastly, although direct accusations are avoided in the framework of the LM, information openness and transparency are intended to lead towards disclosure of government and investor practices. As such, different stakeholders, including local populations, can identify projects, see how funds are spent, and learn about the purpose, cost, and results of each. The possibility of non-respectful 
activities being put in the spotlight should incentivise companies and governments to adapt their practices. Learning from the EITI (Extractive Industries transparency Initiative) (see Schanzenbächer, 2010), the LM is thus also a tool to more responsible investment practices and governance.

By endeavouring to make more information available regarding LSLA, increase transparency and accountability, improve efficiency and effectiveness, inclusive governance and create equitable economic opportunities, the LM aims to contribute to embracing a new development paradigm towards open (data) development.

\section{References}

Anseeuw, W., Alden Wily, L., Cotula, L. and Taylor, M. (2012).Land rights and the rush for land. Rome, International Land Coalition, Research report, 84p.

Anseeuw, W. andBoche, M. (2012).Large-scale land acquisition in Southern Africa. Current state and models implemented. Pretoria, SACAU, Research report, 64p.

Anseeuw, W., Boche, Breu, T., Giger, M., LAY, J., Messerli, P. and Nolte, K. (2012b). Transnational land deals for agriculture in the Global South.Analytical Report based on the Land Matrix Database. Bern/Montpellier/Hamburg, CDE/CIRAD/GIGA, Research report, 64p.

Borras, S. and Franco, J.C. (2010).From Threat to Opportunity? Problems with the idea of a "Code of Conduct" for Land Grabbing.Yale Human Rights and Development Law Journal, Vol.13, No2, pp.50723.

Bott, M., Gigler, S and Young, G (2011). The Role of Crowdsourcing for Better Governance in Fragile States Context. Washington D.C., The World Bank, Open Development Technology Alliance, Draft report, http://www.scribd.com/doc/75642401/The-Role-of-Crowdsourcing-for-Better-Governancein-Fragile-State-Contexts

Bräutigam, D.A. and Xiaoyang, T. (2009).China's Engagement in AfricanAgriculture: "Down to the Countryside". The China Quarterly, 199, September 2009, pp. 686-706.

Chouquer, G. (2012). L'évaluation chifrée des transactions ou concessions massives de terres. Paris, FIEF, Unpublished research report, 14p.

Cotula, L. (2012). The international political economy of the global land rush: A critical appraisal of trends, scale, geography and drivers. Journal of Peasant Studies,Vol.39, No3-4, pp.649-680.

Deininger, K. and Byerlee, D. (2010).Rising global interest in farmland. Can it yield Sustainable and equitable benefits? Washington, The World Bank, Research report, 264p.

De Schutter, O. (2012). How Not to Think of Land-grabbing: Three Critiques of Large-scale Investments in Farmland. Journal of Peasant Studies, Vol.38, No 2, pp. 249-279.

Ducastel, A. and Anseeuw, W. (2011). "Production grabbing " and the transnationalization of (South) African Agriculture.Transcontinentales,No10/11, http://transcontinentales.revues.org/1080.

Gavelin, K., Burall, S. and Wilson, R. (2009). Open Government: Beyond Static Measures. Paris, Organisation for Economic Co-Operation and Development. 
Gigler, B.S., Tanner, R.B. and Kiess, J. (2011a). Enhanced social accountability through open access to data. Washington, The World Bank, Development Outreach, Special issue on "Open Development", September 2011, p.48-52.

Gigler, S; Custer, S. and Rahmetulla, H. (2011b). Realizing the Vision of Open Government DataOpportunities, Challenges and Pitfalls. Washington D.C., The World Bank, Open Development Technology Alliance.

GRAIN (2012). Table: more than 400 large-scale land acquisitions in the World. http://www.grain.org/article/entries/4479-grain-releases-data-set-with-over-400-global-land-grabs. (accessed on March 22, 2012).

Howe, J. (2006). The Rise of Crowdsourcing. Wired Magazine. Issue 14.06, http://www.wired.com/wired/archive/14.06/crowds.html

Huijboom, N. and Van den Broek, T. (2011). Open data: an international comparison of strategies. European Journal of ePractice, No12, March/April 2011.

Maclnnes, M. (2012). Corruption and large-scale land acquisitions: An analysis of the role high level corruption plays in enabling elite capture of land. Ithaca, Cornell University, Conference "Global Land Grabbing II", 17-19 October 2012, 26p.

Oya, C. (2012). Contract Farming in Sub-Saharan Africa: A Survey of Approaches, Debates and Issues. Journal of Agrarian Change, Vol.12, No1, pp. 1-33.

Schanzenbächer, B. (2010). EITI: a model for transparency about investments in agriculture? IISD/Global Donor Platform, e-discussion, response to World Bank report, http://ediscussion.donorplatform.org/?p=714\#respond.

Schönweger, O., Heinimann, A., Epprecht, M., Lu, J. and Thalongsengchanh, P. (2012). Concessions and Leases in the Lao PDR: Taking Stock of Land Investments. Bern and Vientiane, Centre for Development and Environment (CDE), Geographica Bernensia.

White, B., Borras, S.,Hall, R., Scoones, I. and Wolford, W. (2012).The new enclosures: critical perspectives on corporate land deals. Journal of Peasant Studies, Vol.39, No3-4, pp.619-647. 